The Geneva Papers on Risk and Insurance, 19 (No. 70, January 1994), 85 - 98

\title{
The Burden of Proof and the Liability Rule for Suppliers of Services in the EEC
}

\author{
by Christopher Curran *
}

\section{Introduction}

On November 9, 1990, the Commission submitted to the Council of the European Communities a proposal to shift of the burden of proof in cases involving services. Scholars of law and economics have tended to ignore the implications of which party to a legal dispute bears the burden of proof. American tort courts normally expect the plaintiff to prove that the negligence of the defendant caused him injury. However, analyses show that there is no reason a priori that plaintiffs should bear the burden of proof on anything other than proving that there are actual damages. For instance, in situations where little evidence about defendant's actions exists after an accident, it may be less costly for the defendant to prove that he took due care than it is for the plaintiff to attempt to prove that the defendant did not take due care. In these cases, Coase's Theorem would seem to suggest that, since transaction costs are minimized when the defendant bears the burden of proof, the defendant should bear the burden of proving that he did not cause the damages.

It is this very argument, in fact, that seems to be the basis of the Commission's proposal. Unfortunately, the Commission offers no empirical support for this claim. Moreover, as discussed later, shifting the burden of proof to the service suppliers will have the detrimental effects of amount of insurance bundled in service prices and of decreasing the quantity of services demanded. Cost savings, though, are not the only potential benefit from changing the burden of proof to service suppliers. There may be additional benefits if the new rule gives service suppliers more incentives to take due care. It is this last issue that is the focus of this paper. In particular, we use models developed in the law and economics literature to analyze the impact of the proposed change on the caretaking decisions of service providers. Moreover, since the main conclusion of this paper is that shifting the burden will have little effect on the caretaking decisions of service suppliers, justification of the Commission's recommendation awaits further empirical research.

* This paper was presented in an earlier version of this paper presented at the London meetings of the European Association of Law and Economics, September, 1992 and at Georgetown Law School. The author has benefited from comments received at these seminars and especially from Jörg Finsinger, Michael Faure and Paul Rubin. Address any comments to the author at: Department of Economics, Emory University, Atlanta, GA 30322-2240. 
The balance of the paper consists of four sections. The first section reviews the proposal of the Commission. The second section uses existing law and economics literature to construct a simple, game-theoretic model of the legal process. The third section uses this model to explore the impact of shifting the burden of proof from the service buyer to the service seller. The final section offers a summary of the paper's conclusions.

\section{Description of the rule change}

The Commission's proposal' to the Council of the European Communities has four key elements. First, the Commission proposes that the supplier be held liable for damages caused by a "fault committed by him in the performance of the service" (Article 1, Paragraph 1). The effect of this language is to apply a negligence rule to cases involving the supply of services. In particular, the supplier of the service is liable only for damages caused by neglect of his duty to provide the service. Since the negligence standard is the current standard in most countries of the EEC, this portion of the proposal is not a change in existing law.

The second element of the proposal, which forms the nub of the new law, holds that the supplier of the service has the burden of proving he was not at fault in his provision of the service (Article 1, Paragraph 2). For most member countries of the EEC, this rule is a major change that effectively shifts the burden of proof in law cases involving the performance of a service from the plaintiff to the defendant.

The third and fourth elements of the proposal soften the impact of this change on service providers. Under the third element, the injured party has to demonstrate the "causal relationship between the performance of the service and the damage" (Article 5). Moreover, damages include (1) death or direct damage to the health or physical integrity of an individual, (2) damage to privately owned physical property (including animals), and (3) financial damages (Article 4). What is most notable it this description of damages is that they do not appear to allow awards for "pain and suffering." 2

The fourth element of the law reduces or totally eliminates the damages awarded if the injury to the plaintiff is caused jointly by the fault of the supplier and the plaintiff (Article 6, Paragraph 6). Thus, the rule being suggested uses the comparative negligence standard. Since some of the member countries of the EEC already employ a comparative negligence standard, this proposal is an attempt to standardize law throughout the EEC.

In their proposal the Commission offers a brief sketch of their justification for changing the liability rule for services. Since the Commission's justifications include assumptions we use in our analysis, we review their reasoning before proceeding to our analysis. First, the Commission argues that the proposed change in the liability rule for the suppliers of services is a continuation of the implementation of a consumer protection policy at the Community level. In particular, the Commission refers to the 9 November 1989 Council Resolution that connected the safety of services to a "relaunching of the consumer protection policy." 3 The Commission further argues that the existence of different standards in service liability rules among the member nations of the EEC creates barriers to trade in the services.

\footnotetext{
1 Official Journal of the European Communities, No. C (January 18, 1991): 12/8 - 12/11.

2 See Calfee and Rubin (1992) for a discussion of why it is important to exclude damage awards for "pain and suffering" from tort cases.

${ }^{3}$ All the arguments offered in this paragraph are from the proposal. See 1, p. 12/8.
} 
Having established a reason for providing a rule uniform throughout the EEC, the Commission turns to the issue of what this rule should be. The Commission argues that the peculiar nature of product produced justifies reversing the burden of proof of fault in the case of services. In particular, the Commission argues that services are unique, irreplaceable, and vanish "at the moment that damage is caused." 4 Moreover, the Commission argues that the supplier of the service has technical knowledge superior to that held by the purchaser of the service.

Two elements of the Commission's proposal play an important role in the following analysis. The first element is an assumption the Commission makes; the second is a ramification of shifting the burden of proof. First, the argument that the supplier of a service has superior technical knowledge suggests that the Commission believes that shifting the burden of proof reduces the total cost of resolving disputes because it is less costly for the service supplier to provide information to the court about how the service was and ought to have been supplied than it is for the consumer. It is not obvious that claim is correct. Under both rules, the party with the burden of proof probably will rely on the testimony of an expert's evaluation of the level of care taken by the original supplier of the service. Moreover, most likely this expert will be another provider of the service; and, under both rules the service will have "disappeared," leaving an expert with the same difficult job. Thus, it seems more likely that shifting the burden of proof moves the cost of providing the proof from the plaintiff to the defendant without any cost savings. Resolution of this issue depends on empirical evidence that the Commission does not supply. In spite of these misgivings, in the following analysis we consider the implications of the possibility that the Commission is correct in its claim that the service supplier is a cheaper provider of information about care levels than is the plaintiff.

The second element of the Commission's proposal is the implication that shifting the burden of proof will increase the number of circumstances where the supplier of a service is responsible for damages incurred by a consumer. No matter who bears the burden of proof, there are situations where it is impossible to prove conclusively that the supplier of a service did or did not act negligently. There is little reason to believe that the assignment of the burden of proof has any effect on the number of these kinds of cases. First, no matter who bears the burden of proof, the supplier of a service can avoid liability if she can prove she took due care in supplying the service. Thus, if such proof is available to a defendant and the plaintiff's case creates any doubts about the service supplier's care level, she has an incentive to provide this information to the court even when she does not bear the burden of proof. Second, under either system the service supplier has an incentive to keep any records that enable her to prove to a court that she took adequate care in providing the service.

Thus, shifting the burden of proof should have little impact on a service supplier's record keeping or her incentives to provide the court relevant information. As a result, the number of cases where the neither party cannot prove that the supplier did or did not take adequate care in providing the service should not be affected by shifting the burden of proof

\footnotetext{
4 The English version of the Proposal refers to the "one-off" nature of services. This phrase appears to be a typographical error. The German version uses the word unieke. I suspect the English version should read "one-off." See 1, p. 12/8.
} 
to the service supplier. Moreover, since shifting the burden of proof does make the defendant liable in cases where nothing can be proved by either party and the number of these types of cases is independent of who has the burden of proof, shifting the burden of proof from the consumer to the defendant should increase the number of cases where the supplier is responsible for the damages suffered by the consumer.

We can expect that suppliers will respond to the increase in number of cases where they are liable for the damages by increasing the amount of self and third-party insurance coverage. Moreover, supplier will pass the additional insurance costs on to the buyers in the form of higher prices. Thus, as a result the service will have a larger amount of insurance bundled into its final price. As Priest [1992] and Calfee and Rubin [1992] point out, bundling insurance into a product's price creates moral hazard and adverse selection problems that are not present when consumers are responsible for their purchasing their own insurance. ${ }^{5}$ Additionally, the increase in the price of services should decrease the quantity of services demanded. The detrimental effects created by the bundling of insurance into service prices and the reduction in the quantity of services demanded, however, might be eliminated if shifting the burden of proof to service suppliers causes service suppliers to increase their caretaking levels to the socially optimal level. It is this issue that we address in the next section.

\section{A model of the legal process}

In this section, we use the standard law and economics literature to develop a model to examine the expected impact of shifting the burden of proof from an injured buyer to the seller of the service. We model this problem as a sequential move game where a buyer, Mr. B, purchases a service from a seller, Ms. S. We assume that the probability of an accident occurring is a function only of the actions of the service seller. As shown in Figure 1, this game, which we call the "accident game," is a variation of the description of the legal process discussed in Cooter and Rubinfeld [1989]. In the first stage of the game, the seller provides a service at one of two levels of expenditures on caretaking, $\hat{x}$ and $\tilde{x}$, where $\tilde{x}>\hat{x} .{ }^{6}$ Discontinuities in seller's cost functions created by due care standard is the justification for limiting the seller's caretaking decisions to two values (see Brown [1973]). Thus, one can interpret $\tilde{x}$ as the caretaking level expenditures that meet the court's due care standards while $\hat{x}$ is an amount caretaking that is less than the due care standard. After the service is provided, an accident either does or does not occur (i.e., nature moves). The probability an accident costing the buyer an amount " $a$ " occurs is $\tilde{p}^{a}$ if the seller spends $\tilde{x}$ on caretaking and $\hat{p}^{a}$ if he spends $\hat{x}$. By assumption, $\hat{p}^{a}<\tilde{p}^{a}$. If an accident occurs, the buyer has to decide whether to bear the costs of the injury himself or to file a suit. The buyer files a suit by making a demand of $a_{s}$ from the seller. We abstract from the negotiation between the litigants by assuming that the seller has only two alternatives - agree to the demand of $a_{s}$ or

\footnotetext{
5 Two examples of the moral hazard problems include (1) a fully compensated consumer has an incentive to spend too much repairing damages when injuries occur and (2) fully compensating injured through the tort system reduces the role of co-payments. Two examples of the adverse selection problems are (1) the regressive result that wealthy individuals who stand more to lose pay the same rate as those with less to lose and (2) individuals with special expertise cannot purchase more risky services and sign a contract relieving the service provider of legal liability for taking less than the court-established level of care. See Calfee and Rubin [1992].
}

${ }^{6}$ The Appendix contains a table listing the definition of all the variables used in this paper. 
go to trial. If the buyer and seller do not settle the buyer's claim, they go to trial and nature determines the outcome of the trial. If the supplier spent $\tilde{x}$ on caretaking, the buyer will win $a_{t}$ with probability $\tilde{p}^{b}$; if she spent $\hat{x}$ on caretaking, the buyer will win $a_{t}$ with probability $\hat{p}^{b}$. So as to capture the impact of actual caretaking levels on the outcome of a trial, we assume that $\hat{p}^{b}>\tilde{p}^{b}$. Additionally, we assume that the court uses the English rule; thus, the loser of the case pays the winner's court (including filing) costs. ${ }^{7}$

Figure 1 shows the extensive form of the "accident" game. The amounts in parentheses are the payoffs to the seller and the buyer, respectively, for each potential outcome. These payoffs are calculated as follows. The seller's profits are the price she receives for the service, $p$, minus (1) her production costs, $c$, and (2) her caretaking costs, either $\hat{x}$ or $\tilde{x}$, depending on the amount she spends on caretaking. Thus, if there is no accident, the seller receives either $p-c-\hat{x}$ or $p-c-\tilde{x}$. The buyer, on the other hand, values the service at $v$ and receives a payoff of $v-p$ if there is no accident. If an accident occurs and the seller chooses not to file a suit, he receives a payoff of $v-p-a$.

Figure 1: The accident game

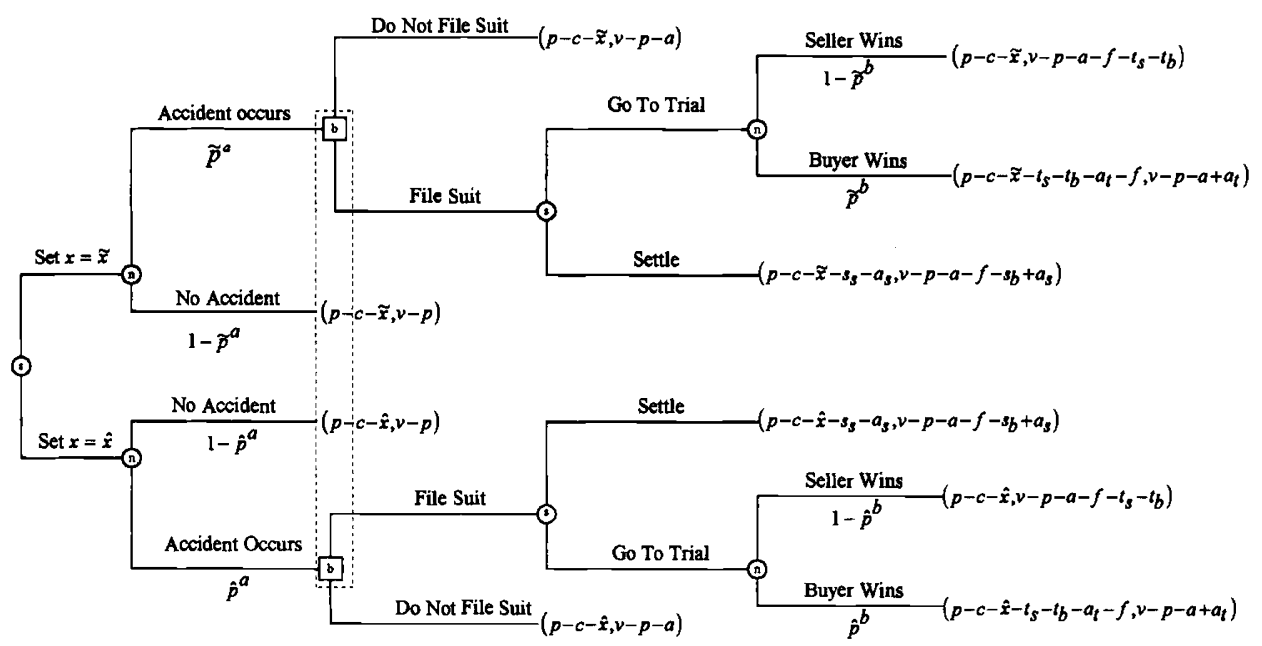

When buyers file suits, both the seller and buyer incur additional costs. In particular, we assume that, if the case settles for $a_{s}$, the seller and buyer incur settlement costs of $s_{s}$ and $s_{b}$, respectively. Moreover, the buyer incurs a filing cost $f$. Thus, when a settlement is the

${ }^{7}$ Most European countries require the loser of a suit to assume the attorney costs of the winner. See Pfennigstorf and Gifford [1991], pp. 157, 165-170, for a listing of the rules in some of the EEC countries. 
outcome, the seller receives a payoff of either $p-c-\hat{x}-s_{s}-a_{s}$ or $p-c-\tilde{x}-s_{s}-a_{s}$, while the buyer receives a payoff of $v-p-a-f-s_{b}+a_{s}$. The seller's two potential payoffs depend on the amount she spends on care.

If the suit goes to court, both parties incur trial costs, $t_{s}$ for the seller and $t_{b}$ for the buyer. We assume that these costs are greater than the settlement costs of $s_{s}$ and $s_{b}$ and that the loser must cover the trial costs of the winner. Thus, if the seller wins, her payoff is either $p-c-\hat{x}$ or $p-c-\tilde{x}$. If she loses, her payoff is $p-c-\hat{x}-f-t_{s}-t_{b}-a_{t}$ or $p-c-\bar{x}-f-$ $t_{s-t b}-a_{t \cdot}{ }^{8}$ The payoff to the buyer if he wins is $v-p-a+a_{t}$; if he loses, his payoff is $v-p-a-f-t_{s}-t_{b}$.

Table 1: Strategies and outcomes of reduced-form of the accident game

\begin{tabular}{|c|c|c|}
\cline { 2 - 3 } \multicolumn{1}{c|}{} & \multicolumn{2}{c|}{ Seller sets care level at : } \\
\hline Buyer offers : & $\hat{x}$ & $\tilde{x}$ \\
\hline$a_{s} \geq \hat{g}$ & Case goes to trial & Case goes to trial \\
\hline$\tilde{g} \leq a_{s}<\hat{g}$ & Case settles & Case goes to trial \\
\hline $0<a_{s}<\tilde{g}$ & Case settles & Case settles \\
\hline$a_{s}=0$ & No case filed & No case files \\
\hline
\end{tabular}

At the time the buyer and seller choose their strategies, they possess different information. First, we assume that the values of (1) the probabilities of an accident occurring, $\hat{p}^{a}$ and $\tilde{p}^{a},(2)$ the probabilities of the buyer winning the suit at trial, $\hat{p}^{b}$ and $\tilde{p}^{b}$, and (3) the values cost of filing $(f)$, settling $\left(s_{s}\right.$ and $\left.s_{b}\right)$, going to trial $\left(t_{s}\right.$ and $\left.t_{b}\right)$, and the settlement and trial awards $\left(a_{s}\right.$ and $\left.a_{t}\right)$ are common knowledge to both the buyer and seller. In contrast, we assume that only the seller knows how much she spent on caretaking. However, we assume that the judge is able to extract enough information from the litigants for the probability of the buyer winning to be lower when the seller spends $\tilde{x}$ on caretaking than when she spends $\hat{x}$. Finally, we assume that the fact that an accident occurs does not imply with certainty that the seller did not take due care. ${ }^{9}$

We solve the accident game via backward induction. First, consider the reaction of a seller to a demand of $a_{s}$ by an injured buyer. The willingness of the seller to settle depends on the amount demanded from her by the injured buyer and on the amount she spent on caretaking. If she spent $\tilde{x}$, then she will accept the buyer's demand only if the sure payoff of settling is greater than the uncertain payoff from going to trial, or if :

\footnotetext{
${ }^{8}$ We assume that a seller who loses a case pays the filing cost incurred by the buyer.

${ }^{9}$ If the buyer is injured, he revises his estimate that the seller choose to set her caretaking level at $\hat{x}$ to: $\operatorname{Pr}(x=\hat{x} \mid$ accident has occurred $)=\frac{\operatorname{Pr}(x=\hat{x}) \hat{p}^{a}}{\operatorname{Pr}(x=\hat{x}) \hat{p}^{a}+[1-\operatorname{Pr}(x=\hat{x})] \tilde{p}^{a}}$

where $\operatorname{Pr}(x=\hat{x})$ is the buyer's estimate of the probability the seller is a negligent seller prior to purchasing the service. While it is possible to frame the accident game in the context of a Bayesian equilibrium, the subsequent analysis does not follow this tact. For more on Bayesian equilibria, see Fudenberg and Tirole [1992], pp. 209-234.
} 


$$
p-c-\tilde{x}-s_{s}-a_{s}>\left(1-\tilde{p}^{b}\right)(p-c-\tilde{x})+\tilde{p}^{b}\left(p-c-\tilde{x}-f-t_{s}-t_{b}-a_{t}\right)
$$

$a_{s}<\tilde{p}^{b}\left(f+t_{s}+t_{b}+a_{t}\right)-s_{s}$

Similarly, if the seller spent $\hat{x}$ on caretaking, she will settle only if :

$$
a_{s}<\hat{p}^{b}\left(f+t_{s}+t_{b}+a_{t}\right)-s_{s}
$$

For notational ease, we define $\hat{g}=\hat{p}^{b}\left(t_{s}+t_{b}+a_{t}+f\right)-s_{s}$ and $\tilde{g}=\tilde{p}^{b}\left(t_{s}+t_{b}+a_{t}+f\right)-s_{s}$. By assumption, $\tilde{p}^{b}<\hat{p}^{b}$, implying that $\tilde{g}<\hat{g}$. The interpretation of $\hat{g}$ and $\tilde{g}$ is straight forward. $\hat{g}$ is the buyer's claim level $\left(a_{s}\right)$ at which a negligent seller (i.e., one who chose a care level expenditure of $\hat{x}$ ) is indifferent between going to trial and settling; $\bar{g}$ is the buyer's claim level at which a nonnegligent seller is indifferent between going to trial and settling. Moreover, since the buyer knows the values of $\hat{g}$ and $\tilde{g}$, he effectively decides whether the case will go to trial when he chooses $a_{s}$.

The implication of the analysis thus far is that the choice of $a_{s}$ by the buyer is a decision by him on whether he wants go to trial or to settle. Moreover, since the fact that an accident has occurred does not necessarily mean that the seller was negligent (i. e., spent $\hat{x}$ on caretaking), the buyer can choose his strategy (the level of $a_{s}$ ) at the same time as the seller chooses the amount she will spend on caretaking. These two observations allow us to reduce the extensive-form game shown in Figure 1 to the strategic-form game shown in Table 1 . In this game the seller's strategy set is $\{x \in(\hat{x}, \tilde{x})\}$ while the buyer's strategy set is $\left\{a_{s} \in 0 \leq a_{s} \leq \hat{g}\right\}$. Table 1 lists the outcomes implied by the two strategy sets; Table 2, the expected payoffs from the two strategy sets for the seller and buyer, $\pi^{s}\left(x, a_{s}\right)$ and $\pi^{b}\left(x, a_{s}\right)$ respectively.

Figure 2 shows the graphs of two potential types of expected payoff functions for the seller while Figure 3 shows the graphs of two potential types of expected payoff functions for the buyer. Consider Figure 2 first. In panel (a) the payoff to the seller of setting her care level at $\hat{x}$ is greater than the payoff to setting her care level at $\tilde{x}$ no matter what claim $\left(a_{s}\right)$ she expects an injured buyer to make. In panel (b) the two payoff curves intersect at $a_{s}^{*} .10$ Thus, if the seller expects an injured buyer to make a claim less than $a_{s}^{\prime}$, she will set her caretaking level at $\hat{x}$; otherwise, she will set her caretaking level at the more costly $\tilde{x}$. We call the two types of sellers type " $a$ " and type " $b$ " sellers, where the " $a$ " and " $b$ " match the panels in Figure 2. Figure 3 shows that a similar situation exists for the buyer. In panel (a) the payoff to the buyer if the seller sets her caretaking level at $\tilde{x}$ is strictly greater than the payoff to him if the seller sets her caretaking level at $\hat{x}$. In panel (b) the two payoff functions intersect at a claim level of $a_{s}^{\prime \prime}$ : if the seller set her caretaking level at $\tilde{x}$, the buyer is better off making a claim less than $a_{s}^{\prime \prime}$; if the seller set her caretaking level at $\hat{x}$, the buyer is better off making a claim greater than $a_{s}{ }^{\prime}{ }^{11}$ As before, we call the two types of buyers type " $a$ " and type " $b$ " buyers, where the " $a$ " and " $b$ " match the panels in Figure 3.

The fact that, while knowing their own type, neither player knows what type the other player is at the time they choose their strategy introduces two additional elements of uncertainty into the game. First, neither the buyer nor the seller knows what type the other player is. Second, if the buyer thinks the seller is a type " $b$ " buyer, she does not know the

${ }^{10}$ Figure 2 shows the payoff functions intersecting at an $a_{s}$ between $\tilde{g}$ and $\hat{g}$. It is also possible for the curves to intersect at an $a_{s}$ less than $\tilde{g}$.

${ }^{11}$ As true in the case of the seller's payoff functions, the buyer's payoff functions can intersect at any value of $a_{s}$ less than $\hat{g}$. 
value of $a_{s}^{\prime}$. Similarly, if the seller thinks the buyer is a type " $b$ " buyer, she does not know the value of $a$ ". We model this uncertainty by assuming that the distribution of type " $a$ " sellers is common knowledge to both buyers and sellers. In particular, we assume that the percentage of type " $a$ " sellers is $\theta$.

We now search for potential Nash equilibria. The buyer's problem is to choose a claim strategy, $a_{s}$, that maximizes his expected payoff :

$$
\underset{a_{\mathrm{s}}}{\operatorname{Max}} E \pi^{b}\left(x, a_{s}\right)=\theta \pi^{b}\left(\hat{x}, a_{s}\right)+(1-\theta)\left[P\left(a_{s} \leq a_{s}^{\prime}\right) \pi^{b}\left(\hat{x}, a_{s}\right)+P\left(a_{s} \geq a_{s}^{\prime}\right) \pi^{b}\left(\tilde{x}, a_{s}\right)\right]
$$

Table 2: Expected payoffs of the reduced-form of the accident game, $\pi^{s}\left(x, a_{s}\right)$ and $\pi^{b}\left(x, a_{s}\right)$

\begin{tabular}{|c|c|c|}
\hline & Seller sets care level at : \\
\hline $\begin{array}{c}\text { Buyer } \\
\text { offers }\end{array}$ & $\hat{x}$ & $\tilde{x}$ \\
\hline$a_{s}>\hat{g}$ & $\begin{array}{c}p-c-\hat{x}-\hat{p}^{a} \hat{p}^{b}\left(f+a_{t}+t_{s}+t_{b}\right), \\
v-p-\hat{p}^{a}\left(a-\hat{p}^{b} a_{t}\right)-\hat{p}^{a}\left(1-\hat{p}^{b}\right)\left(f+t_{b}+t_{s}\right)\end{array}$ & $\begin{array}{c}p-c-\tilde{x}-\tilde{p}^{a} \tilde{p}^{b}\left(f+a_{t}+t_{s}+t_{b}\right), \\
v-p-\tilde{p}^{a}\left(a-\tilde{p}^{b} a_{t}\right)-\tilde{p}^{a}\left(1-\tilde{p}^{b}\right)\left(f+t_{b}+t_{s}\right)\end{array}$ \\
\hline$\hat{\mathrm{g}} \leq a_{s} \leq \hat{g}$ & $\begin{array}{c}p-c-\hat{x}-\hat{p}^{a}\left(s_{s}+a_{s}\right), \\
v-p-\hat{p}^{a}\left(a+f+s_{b}-a_{s}\right)\end{array}$ & $\begin{array}{c}p-c-\tilde{x}-\tilde{p}^{a} \tilde{p}^{b}\left(f+a_{t}+t_{s}+t_{b}\right), \\
v-p-\tilde{p}^{a}\left(a-\tilde{p}^{b} a_{t}\right)-\tilde{p}^{a}\left(1-\tilde{p}^{b}\right)\left(f+t_{b}+t_{s}\right)\end{array}$ \\
\hline $0<a_{s}<\tilde{g}$ & $\begin{array}{c}p-c-\hat{x}-\hat{p}^{a}\left(s_{s}+a_{s}\right), \\
v-p-\hat{p}^{a}\left(a+f+s_{b}-a_{s}\right)\end{array}$ & $\begin{array}{c}p-c-\tilde{x}-\tilde{p}^{a}\left(s_{s}+a_{s}\right), \\
v-p-\tilde{p}^{a}\left(a+f+s_{b}-a_{s}\right)\end{array}$ \\
\hline$a_{s}=0$ & $\begin{array}{c}p-c-\hat{x}, \\
v-p-\hat{p}^{a} a\end{array}$ & $\begin{array}{c}p-c-\tilde{x}, \\
v-p-\tilde{p}^{a} a\end{array}$ \\
\hline
\end{tabular}

or:

$$
\underset{a_{\mathrm{s}}}{\operatorname{Max}} E \pi^{b}\left(x, a_{s}\right)=\left[\theta+(1-\theta) P\left(a_{s} \leq a_{s}^{\prime}\right)\right] \pi^{b}\left(\hat{x}, a_{s}\right)+\left[(1-\theta) P\left(a_{s} \geq a_{s}^{\prime}\right)\right] \pi^{b}\left(\tilde{x}, a_{s}\right)
$$

The buyer's expected payoff function, thus, is a convex combination of $\pi^{b}\left(\hat{x}, a_{s}\right)$, the payoff he will receive if the seller sets her care level at $\hat{x}$, and $\pi^{b}\left(\tilde{x}, a_{s}\right)$, the payoff he will receive if the seller sets her care level at $\tilde{x}$. Examination of Figure 3 shows that, as long as $\theta$ is positive (i. e., sellers of type (a) exist), there is a chance that the buyer will face a seller that will always set her care level at $\hat{x}$. In this case, the buyer's expected payoff function increases until $a_{s}$ is set equal to $\hat{g}$, the claim level at which the buyer is indifferent between whether a case goes to trial or settles.

The seller's problem is to choose $a x \in(\hat{x}, \tilde{x})$ that maximizes her expected payoff, given that the buyer will choose a strategy of setting $a_{s}$ equal to $\hat{g}$. We see from Figure 2 that type (a) sellers will set their care level at $\hat{x}$, while type (b) sellers will set their care level at $\tilde{x}$. Thus, if $\theta$ is positive, the strategy set of type (a) seller sets her care level at $\hat{x}$ and type (b) seller sets her care level at $\tilde{x}$ while the buyer always sets his claim at $\hat{g}$ is a Nash equilibrium. 
Figure 2: Types of seller's expected payoff functions.

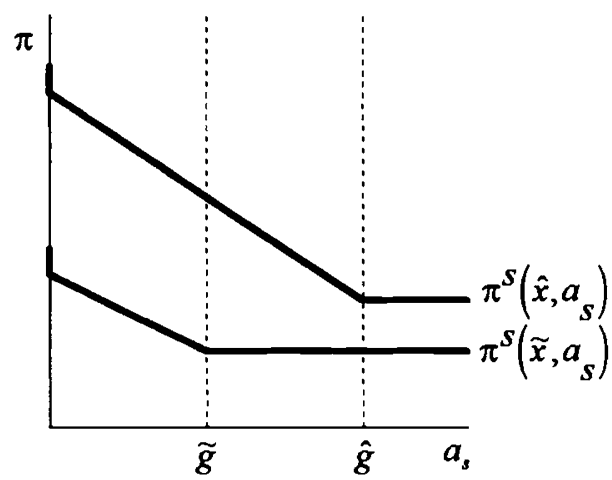

(a)

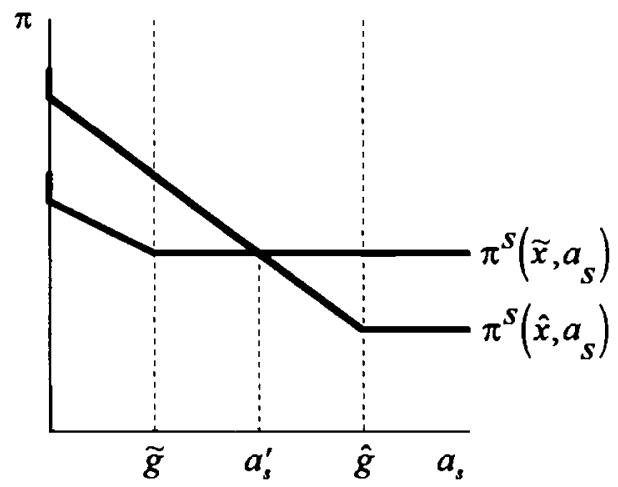

(b)

Similar arguments hold if $\theta$ is zero (i. e., type (a) sellers do not exist). In this case the seller's expected payoff function is :

$$
\underset{a_{s}}{\operatorname{Max}} E \pi^{b}\left(x, a_{s}\right)=P\left(a_{s} \leq a_{s}^{\prime}\right) \pi^{b}\left(\hat{x}, a_{s}\right)+P\left(a_{s} \geq a_{s}^{\prime}\right) \pi^{b}\left(\tilde{x}, a_{s}\right)
$$

As earlier, the expected payoff function is a convex combination of the payoffs to the buyer if the seller sets her caretaking level at $\hat{x}$ and if she sets it at $\tilde{x}$. The expected payoff function to the buyer has a maximum when $a_{s}$ equals $\hat{g}$. If the buyer chooses the strategy of setting $a_{s}$ equal to $\hat{g}$, the seller will maximize her expected payoff by setting her caretaking level at $\tilde{x}$. Moreover, if the buyer expects the seller to set her caretaking level at $\tilde{x}$, he does not have an incentive to change his strategy from setting $a_{s}$ equal to $\hat{g}$. Thus, the strategy set seller sets her caretaking level at $\tilde{x}$ and the buyer sets $a_{s}$ at $\hat{g}$ is a Nash Equilibrium.

Figure 3: Types of potential buyer's expected payoff functions.

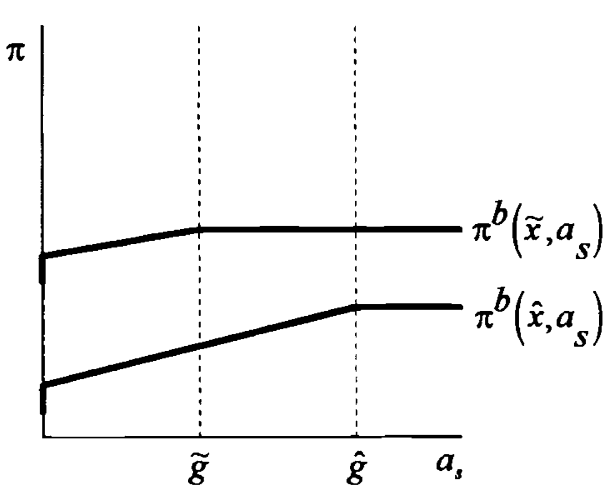

(a)

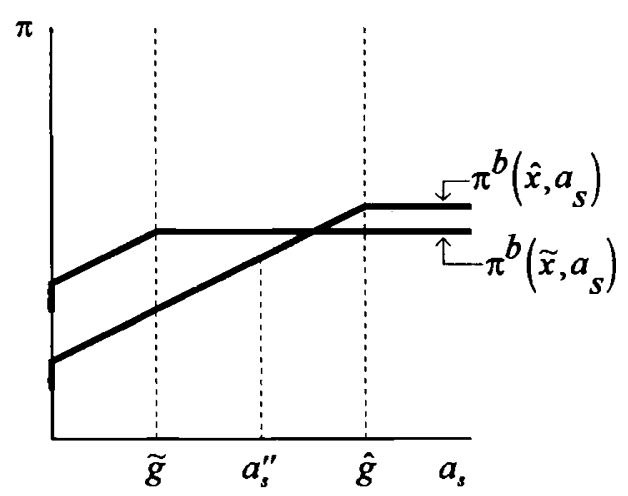

(b) 


\section{The impact of shifting the burden of proof}

We model the impact of shifting the burden of proof to the seller as having two effects on the cost structure of the accident. First, accepting the implicit argument of the Commission, we assume that shifting the burden of proof will reduce the trial costs for the buyer by an amount greater than it increases the trial costs of the seller. Second, we assume that shifting the burden of proof will reduce the costs to the buyer of filing a case. In short, we model the impact of a shift of the burden of proof as a decrease in the sum $\left(f+t_{b}+t_{s}\right)$.

Figure 4: Impact of a shift in the burden of proof on the seller's payoff functions

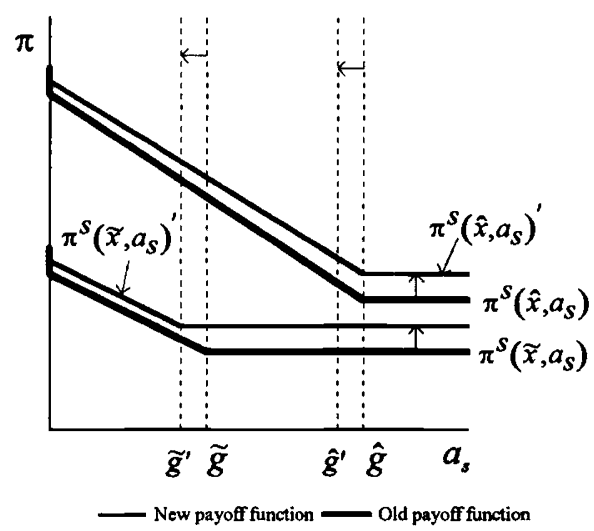

(a)

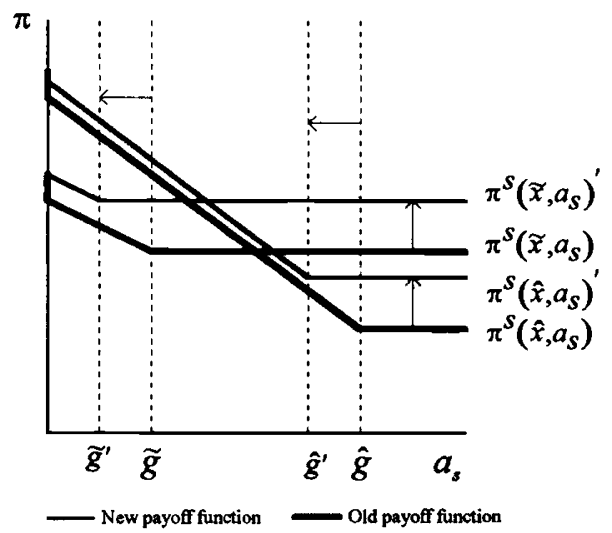

(b)

Figures 6 and 7 show the impact in the reduction of $\left(f+t_{b}+t_{s}\right)$ on the payoffs of both types sellers and buyers. First, the decrease in $\left(f+t_{b}+t_{s}\right)$ causes both $\hat{g}$ and $\tilde{g}$ to shift to the left, although $\hat{g}$ falls by a larger amount. ${ }^{12}$ Moreover, the payoff curves for both the buyer and seller shift up. ${ }^{13}$ In the case of the buyer, the relative size of the two shifts is uncertain; in the case of the buyer, the shift in $\pi^{s}\left(\hat{x}, a_{s}\right)$ is relatively larger than the shift in $\pi^{s}\left(\tilde{x}, a_{s}\right)$.

12 By definition $\hat{g}=\hat{p}^{b}\left(f+t_{s}+t_{b}+a_{t}\right)$ and $\tilde{g}=\tilde{p}^{b}\left(f+t_{s}+t_{b}+a_{t}\right)$. Thus, $\frac{\partial \hat{g}}{\partial\left(f+t_{s}+t_{b}+a_{t}\right)}=\hat{p}^{b}$ and $\frac{\partial \tilde{g}}{\partial\left(f+t_{s}+t_{b}+a_{t}\right)}=\bar{p}^{b}$. Since, by assumption, $\hat{p}^{b}>\bar{p}^{b}, \frac{\partial \hat{g}}{\partial\left(f+t_{s}+t_{b}+a_{t}\right)}>\frac{\partial \tilde{g}}{\partial\left(f+t_{s}+t_{b}+a_{t}\right)}$.

13 The payoffs in Table 2 imply: $\frac{\partial \pi^{s}(\hat{x}, \hat{g})}{\partial\left(f+t_{s}+t_{b}+a_{t}\right)}=-\hat{p}^{a} \hat{p}^{b}<0, \frac{\partial \pi^{s}(\tilde{x}, \hat{g})}{\partial\left(f+t_{s}+t_{b}+a_{t}\right)}=-\tilde{p}^{a} \bar{p}^{b}<0$, $\frac{\partial \pi^{b}(\hat{x}, \hat{g})}{\partial\left(f+t_{s}+t_{b}+a_{l}\right)}=-\hat{p}^{a}\left(1-\hat{p}^{b}\right)<0$, and $\frac{\partial \pi^{s}(\tilde{x}, \tilde{g})}{\partial\left(f+t_{s}+t_{b}+a_{t}\right)}=-\tilde{p}^{a}\left(1-\tilde{p}^{b}\right)<0$. Since $\hat{p}^{b}>\tilde{p}^{b}$ and $\hat{p}^{a}>\tilde{p}^{a}$, we get that $\left|\frac{\partial \pi^{s}(\hat{x}, \hat{g})}{\partial\left(f+t_{s}+t_{b}+a_{t}\right)}\right|>\left|\frac{\partial \pi^{s}(\tilde{x}, \tilde{g})}{\partial\left(f+t_{s}+t_{b}+a_{t}\right)}\right|$. The relative sizes of the other two partial derivatives are uncertain. 
Figure 5:

Impact of a shift in the burden of proof on the buyers payoff functions if $\left(f+t_{b}+t_{s}\right)$ decreases

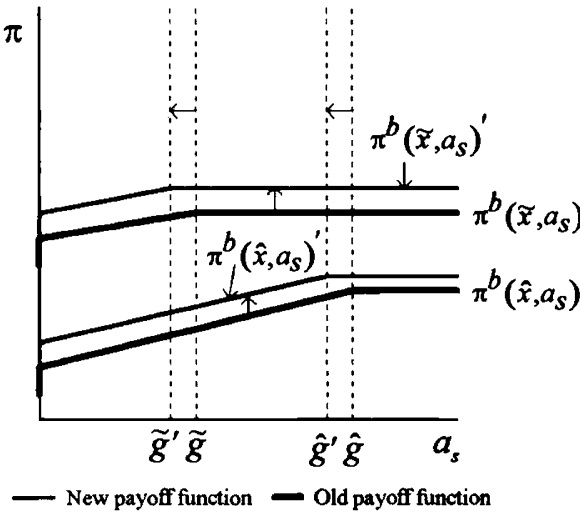

(a)

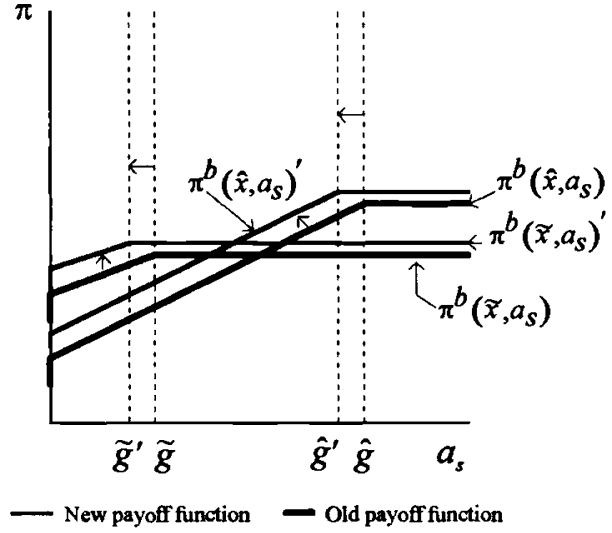

(b)

Figure 6:

Impact on potential seller's expected payoff functions of an increase in $\tilde{p}^{b}$ and $\hat{p}^{b}$

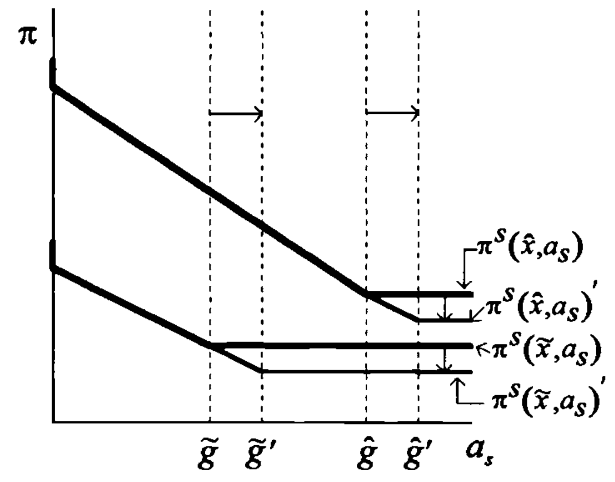

New payoff function $\longrightarrow$ Old payoff function

(a)

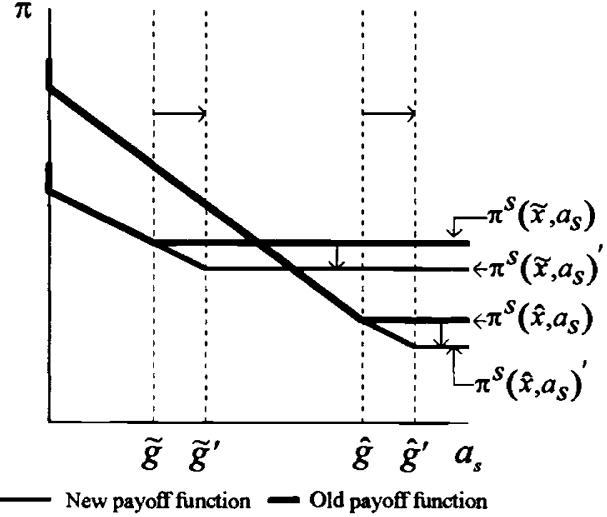

(b)

The analysis of the accident game after the burden of proof has been shifted to the seller follows the same logic as before. Essentially, the Nash equilibria described above remain. The buyer has the incentive to claim the new, lower $\hat{g}$, while the seller will choose $\hat{x}$ if she is a type (a) seller and $\tilde{x}$ if she is a type (b) seller. Thus, in this model shifting the burden of proof will reduce the level of claims made without changing the level of care taken by service providers. 
Figure 7: Impact on potential buyer's expected payoff functions of an increase in $\tilde{p}^{b}$ and $\hat{p}^{b}$

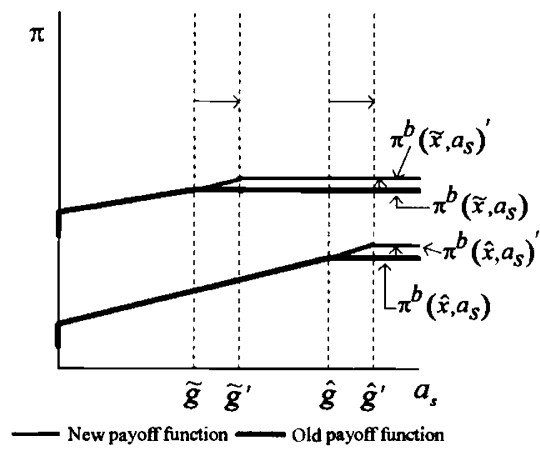

(a)

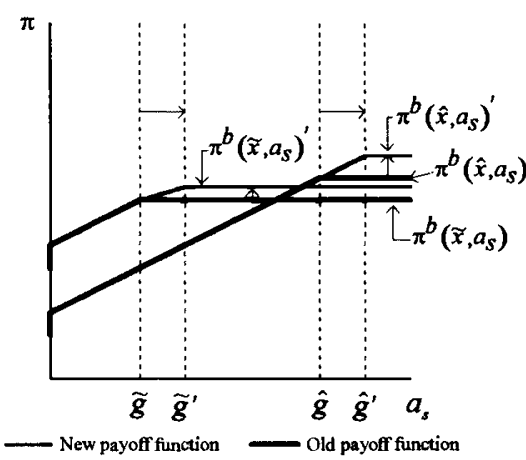

(b)

\section{Summary and conclusions}

There are three caveats to the above discussion. First, the analysis ignores the impact of the change in burden of proof on efforts made by the plaintiff and defendant during a trial. Existing models of trials do not preclude the possibility that shifting the burden of proof to the defendant will increase the trial efforts of either party enough to alter the probabilities that the buyer will win the trial, $\tilde{p}^{b}$ and $\hat{p}^{b}$. While such an outcome is theoretically possible, it seems unlikely. The second caveat is that the result that shifting the burden of proof will not affect the level of care taken by the supplier hangs by slender theoretical threads. The doubt associated with this model is the same as is attached to most game theory analyses. Different assumptions about the information available to the seller and buyer or use of different equilibria concepts can generate alternative results. ${ }^{14}$ Indeed, this paper has not attempted to analyze all the possible models or to empirically test these models. Thus, like almost all game theory our results are at best suggestive. The third caveat is that the model assumes that buyers cannot take any actions that affect the probability of an accident occurring. While such an assumption may match the belief by some that service purchasers are helpness consumers, there is adequate evidence available to suggest that consumers can reduce the likelihood of injury by adequately researching a service supplier's reputation.

Given these three caveats, this paper suggests that the proposed shift of burden of proof in cases involving the suppliers of services will have little or no effect on caretaking by service suppliers. Thus, if there are benefits to shifting the burden of proof from the service buyers to service sellers, they must be due to the reduction in court costs claimed by the Commission. However, since there is no empirical evidence to support the Commission's claim (assumption), justification for spending resources to change the burden of proof awaits further research. Moreover, shifting the burden of proof will have the detrimental effects of increasing the amount of insurance bundled in service prices and decreasing the demand for services. Thus, on balance the worth of the Commission's proposal remains an unresolved empirical issue.

14 Additionally, it is not clear that any of the equilibrium concepts used in game theory successfully predict human behavior. 
Appendix: Definition of variables

\begin{tabular}{|c|c|}
\hline Variable & Definition \\
\hline$\hat{x}$ & amount spent on caretaking by a negligent service seller \\
\hline $\bar{x}$ & amount spent on caretaking by a nonnegligent service seller \\
\hline$p$ & price of the service \\
\hline$c$ & production cost to the seller of producing the service \\
\hline$v$ & value of the service to the buyer \\
\hline$a$ & losses suffered by a buyer when injured \\
\hline$f$ & cost to an injured buyer to file a claim \\
\hline$\hat{p}^{a}$ & probability of an accident occurring if seller sets caretaking at $\hat{x}$ \\
\hline$\tilde{p}^{a}$ & probability of an accident occurring if seller set caretaking at $\tilde{\mathbf{x}}$ \\
\hline$s_{s}$ & seller's cost of settling \\
\hline$s_{b}$ & buyer's cost of settling \\
\hline$a_{s}$ & amount received by buyer if buyer and seller settle out of court \\
\hline$t_{b}$ & buyer's trial costs \\
\hline$t_{s}$ & seller's trial costs \\
\hline$a_{t}$ & amount buyer receives if he wins case at trial \\
\hline$\pi^{b}$ & buyer's expected payoff \\
\hline$\pi^{s}$ & seller's expected payoff \\
\hline$a_{s}^{\prime}$ & $a_{s}$ value where type (b) seller's payoff functions intersect (see Figure 2) \\
\hline$a_{s}^{\prime \prime}$ & $a_{\mathrm{s}}$ value where type (b) buyer's payoff functions intersect (see Figure 3 ) \\
\hline$\theta$ & percent of type (a) sellers \\
\hline
\end{tabular}




\section{REFERENCES}

CALFEE, John E. and RUBIN, Paul H. 1992. "Some Implications of Damage Payments for Nonpecuniary Losses," The Journal of Legal Studies $12: 371$.

COOTER, Robert. 1987. "Why Litigants Disagree: A Comment on George Priest's 'Measuring Legal Change'," Journal of Law, Economics and Organization 3:227.

COOTER, Robert D. and RUBINFELD, Daniel L. 1989. "Economic Analysis of Legal Disputes and Their Resolution." Journal of Economic Literature 27 : 1067.

COOTER, Robert D. and ULEN, Thomas S. 1986. "The Economic Case for Comparative Negligence." New York Law Review 61: 1067.

CROLEY, S. P. and HANSON, J. D. 1991. "What Liability Crises? An Alternative Explanation of Recent Events in Products Liability." Yale Journal on Liability $8: 1$.

FUDENBERG, Drew and TIROLE, Jean. 1992. Game Theory. Cambridge, MA: The MIT Press, 1992.

HADDOCK, David and CURRAN, Christopher. 1985. "An Economic Theory of Comparative Negligence." Journal of Legal Studies $14: 49$.

HYLTON, Keith N. 1990. "Costly Litigation and Legal Error under Negligence," Journal of Law, Economics and Organization 6: 433.

MAGEE, Stephen, BROCK, Williams A. and YOUNG, Leslie A. 1989. Black Hole Tariffs and Endogenous Policy Theory: Political Economy in General Equilibrium, Cambridge: Cambridge University Press.

PELTZMAN, Sam. 1991. "The Handbook of Industrial Organization: A Review Article." Journal of Political Economy 99 : 201.

PFENNIGSTORF, Werner with GIFFORD, Donald G. 1991. A Comparative Study of Liability Law and Compensation Schemes in Ten Countries and the United States, Oak Brook, IL: Insurance Research Council.

POLINSKY, A. Mitchel and RUBINFELD, Daniel L. 1988. "The Welfare Implications of Costly Litigation for the Level of Liability." Journal of Legal Studies 17:151.

P'NG, I.P.L. 1986. "Optimal Subsidies and Damages in the Presence of Judicial Error," International Review of Law and Economics $6: 101$.

PRIEST, George. 1987. "The Current Insurance Crisis and Modern Tort Law." Yale Law Journal $96: 1521$.

PRIEST, George. 1992. "Can Absolute Manufacturer Liability be Defended?" Yale Journal on Regulation $9: 237$.

REA, Samuel A. 1987. "The Economics of Comparative Negligence." International Review of Law and Economics $7: 149$.

ROLPH, John E. 1991. "Merit Rating for Physicians; Malpractice Premiums: Only a Modest Deterrent," Law \& Contemporary Problems 54: 65.

RUBIN, Paul. 1992. Tort Reform by Contract. Forthcoming from the American Enterprise Institute.

RUBINFELD, Daniel L. 1987. "The Efficiency of Comparative Negligence." Journal of Legal Studies $16: 375$.

SHAVELL, Steven. 1989. "Optimal Sanctions and the Incentive to Provide Evidence to Legal Tribunals." International Review of Law and Economics 9:3-11. 